\title{
Oxytocin Reduces Alcohol Cue-Reactivity in Alcohol-Dependent Rats and Humans
}

\author{
Anita C Hansson ${ }^{*, 1}$, Anne Koopmann², Stefanie Uhrig', Sina Bühler², Esi Domi ${ }^{3,6}$, Eva Kiessling', \\ Roberto Ciccocioppo ${ }^{3}$, Robert C Froemke ${ }^{4}$, Valery Grinevich ${ }^{5}$, Falk Kiefer ${ }^{2}$, Wolfgang H Sommer ${ }^{1,2}$, \\ Sabine Vollstädt-Klein ${ }^{2,7}$ and Rainer Spanagel ${ }^{1,7}$ \\ IInstitute of Psychopharmacology, Central Institute of Mental Health, Medical Faculty Mannheim, University of Heidelberg, Mannheim, Germany; \\ ${ }^{2}$ Department of Addictive Behavior and Addiction Medicine, Central Institute of Mental Health Mannheim, Medical Faculty Mannheim, University \\ of Heidelberg, Mannheim, Germany; ${ }^{3}$ School of Pharmacy, Pharmacology Unit, University of Camerino, Camerino, Italy; ${ }^{4}$ Department of \\ Otolaryngology, Skirball Institute for Biomolecular Medicine, Neuroscience Institute, New York University School of Medicine, New York, NY, USA; \\ ${ }^{5}$ Schaller Research Group on Neuropeptides, German Cancer Research Center (DKFZ), Heidelberg, Germany
}

Approved pharmacological treatments for alcohol use disorder are limited in their effectiveness, and new drugs that can easily be translated into the clinic are warranted. One of those candidates is oxytocin because of its interaction with several alcohol-induced effects. Alcoholdependent rats as well as post-mortem brains of human alcoholics and controls were analyzed for the expression of the oxytocin system by qRT-PCR, in situ hybridization, receptor autoradiography ([ $\left.{ }^{125} \mid\right]$ OVTA binding), and immunohistochemistry. Alcohol self-administration and cue-induced reinstatement behavior was measured after intracerebroventricular injection of $10 \mathrm{nM}$ oxytocin in dependent rats. Here we show a pronounced upregulation of oxytocin receptors in brain tissues of alcohol-dependent rats and deceased alcoholics, primarily in frontal and striatal areas. This upregulation stems most likely from reduced oxytocin expression in hypothalamic nuclei. Pharmacological validation showed that oxytocin reduced cue-induced reinstatement response in dependent rats - an effect that was not observed in nondependent rats. Finally, a clinical pilot study (German clinical trial number DRKS00009253) using functional magnetic resonance imaging in heavy social male drinkers showed that intranasal oxytocin $(24 \mathrm{IU})$ decreased neural cue-reactivity in brain networks similar to those detected in dependent rats and humans with increased oxytocin receptor expression. These studies suggest that oxytocin might be used as an anticraving medication and thus may positively affect treatment outcomes in alcoholics.

Neuropsychopharmacology (2018) 43, 1235-1246; doi:I0.1038/npp.2017.257; published online 20 December 2017

\section{INTRODUCTION}

Alcohol use and abuse account for a tremendous burden of disease worldwide. Excessive alcohol drinking is a leading risk factor for chronic non-communicable diseases and is linked to more than 60 diseases, including cancers, cardiovascular diseases, liver cirrhosis, neuropsychiatric disorders, and fetal alcohol syndrome. One further consequence of excessive alcohol use is that 76 million adults worldwide are alcohol dependent (Rehm et al, 2009). Alcohol dependence is characterized by cycles of excessive alcohol consumption, interspersed with intervals of abstinence, and

*Correspondence: Dr AC Hansson, Institute of Psychopharmacology, Central Institute for Mental Health (ZI), Medical Faculty Mannheim, University of Heidelberg, Square J5, Mannheim 68159, Germany. Tel: +49 621 1703 6293, Fax: +49621 1703 6255,

E-mail: anita.hansson@zi-mannheim.de

${ }^{6}$ Current address: Center for Social and Affective Neuroscience, Institute for Clinical and Experimental Medicine, Linkoping University, Linkoping 58I83, Sweden.

${ }^{7}$ These authors contributed equally to this work.

Received 31 March 2017; revised 8 October 2017; accepted 24 October 2017; accepted article preview online I November 2017 frequent relapses (Heilig et al, 2010). Relapse is a key element of this disease process and blocking relapse is therefore a key objective for the treatment of alcohol-dependent patients. Currently, there are four antirelapse medications approved by the US Food and Drug Administration to treat alcohol dependence: disulfiram, oral naltrexone, a long-lasting injectable naltrexone, and acamprosate. These drugs have small to medium effect sizes and only a minority of patients benefit from these treatments (Litten et al, 2012). Another problem is that there is a huge treatment gap-most alcoholics do not seem to obtain appropriate treatment (van Amsterdam and van den Brink, 2013). Given this situation, new drugs that can be easily translated into clinical application are warranted. One of those candidates is oxytocin (OXT), because this drug interacts with several effects induced by alcohol and has already been applied in many clinical settings.

OXT is a neuropeptide that has important and welldocumented roles in mammalian social behavior and various other central and peripheral processes (Meyer-Lindenberg et al, 2011; Neumann and Landgraf, 2012; Grinevich et al, 2016). Numerous studies in rodents have found that OXT 
alters neuroadaptation to drugs of abuse including alcohol, and that OXT is a potential mediator and modulator of addictive behavior (Sarnyai, 2011; Sarnyai and Kovacs, 2014). Indeed, peripheral as well as central administration of OXT blocks the development of tolerance to the hypothermic and hypnotic effects of alcohol in rodents and modulates the severity of alcohol withdrawal, demonstrating that OXT alters neuroadaptations to alcohol (Bowen et al, 2015). Very recently, it has been shown that acute intranasal OXT treatment, which leads to a substantial increase of OXT in the cerebrospinal fluid (Striepens et al, 2013), also reduces withdrawal symptoms in alcohol-dependent patients (Pedersen et al, 2013). Several studies further found an OXT-dependent increase of functional connectivity between the amygdala and insular cortex, orbitofrontal cortex, anterior cingulate cortex $(\mathrm{Cg})$, nucleus caudatus $(\mathrm{NC})$, and hippocampus, which all are regions relevant in alcohol cuereactivity and the development of craving (Bethlehem et al, 2013). These findings suggest that OXT might decrease cuereactivity and craving in social drinkers.

Here we set out to systematically study neuroadaptive changes in the OXT system in alcohol-dependent individuals in brain sites that are relevant for mediating alcohol reinforcement and addictive behavior (Koob and Volkow, 2010). For this we quantified mRNA and protein levels of OXT and OXT receptors (OXTRs) in brain tissue from abstinent alcohol-dependent rats and deceased alcoholics. We then studied the effects of OXT on alcohol-seeking behavior in the reinstatement paradigm (Sanchis-Segura and Spanagel, 2006). For animal behavior experiments, we used the so-called 'post-dependent animal model' (Heilig and Koob, 2007) where dependence is induced through repeated intermittent cycles of alcohol vapor exposure. This model has already been proven valuable in the investigation of several neurotransmitter systems (Sommer et al, 2008; Hermann et al, 2012; Meinhardt et al, 2013; Hirth et al, 2016; Uhrig et al, 2017), and is used as a model for medication development in alcoholism (Meinhardt and Sommer, 2015). Additionally, in a pilot study in nontreatment seeking heavy social drinkers, we examined neural cue-reactivity, which was previously shown to be associated with subsequent craving and relapse in alcohol-dependent patients (Grüsser et al, 2004; Reinhard et al, 2015). Here we applied functional magnetic resonance imaging (fMRI) to measure neural reactivity to alcohol-related cues following intranasal administration of a single dose of OXT conducted in a crossover design with placebo control. The major hypothesis was a reduction of cue-reactivity following the presentation of alcohol cues by a single dose of OXT compared with placebo.

\section{MATERIALS AND METHODS}

Human post-mortem brain samples of 27 male Caucasians (13 alcoholics and 14 controls) were obtained from the NSW Tissue Resource Center (University of Sydney, Australia; see Supplementary Table S1; Hermann et al, 2017), and analyzed for OXTR expression by quantitative RT-PCR (qRT-PCR) and receptor autoradiography ([ $\left[{ }^{125} \mathrm{I}\right] \mathrm{OVTA}$ binding) according to Olazabal and Young (2006b) and Uhrig et al (2016).
In male Wistar rats, alcohol dependence was induced by exposure to chronic intermittent cycles of alcohol inhalation and rats were killed at different time points of abstinence $(0,1$, 3,7 , and 21 days after the last vapor exposure according to Hansson et al, 2010; Hermann et al, 2012; Hirth et al, 2016; Uhrig et al, 2017) for OXT and OXTR expression analysis by in situ hybridization, receptor autoradiography, western blotting, and OXT immunohistochemistry. Additionally, cueinduced reinstatement after intracerebroventricular injection of either $10 \mathrm{nM}$ OXT or vehicle (aCSF) was performed in 3 weeks abstinent rats. The experiments were conducted in accordance with the European ethical guidelines for the care and use of laboratory animals, and were approved by the local animal care committee (Regierungspräsidium Karlsruhe, Germany, license number 35-9185.81/G-302/15 and AZ 35-9185.81/G-183/09).

For the clinical study, 12 heavy social drinkers were recruited at the Central Institute of Mental Health (Mannheim, Germany), for fMRI studies on alcohol cue-induced activation after a single application of intranasal OXT according to Sauer et al (2013) (German clinical trial number DRKS00009253; URL: https://www.drks.de/drks_web). All experimental procedures and statistics are described in detail in Supplementary Information.

\section{RESULTS}

\section{Animal Studies}

OXTR is increased and the endogenous ligand OXT is decreased in abstinent rats. We used the post-dependent animal model-a well-established rat model for alcohol dependence (Rimondini et al, 2002; Meinhardt et al, 2013; Hirth et al, 2016; Uhrig et al, 2017). Rats were exposed to 7 weeks of intermittent cycles of alcohol vapor to induce dependence, reaching blood alcohol concentrations (BACs) of $266.2 \pm 12.6 \mathrm{mg} / \mathrm{dl}$. Three weeks after the last vapor exposure, rats were killed in abstinence to investigate changes in the expression of OXT peptide and OXTRs at both the mRNA and protein levels. Forebrain regions related to reward circuits (Noori et al, 2012) were used for in situ hybridization, receptor autoradiography (Uhrig et al, 2016), western blotting, and immunohistochemistry experiments (see Supplementary Figure S1). Semiquantitative analysis of the Oxtr mRNA revealed an increase in alcohol-dependent animals in the medial prefrontal cortex (cingulate cortex (Cg): 22\% increase; prelimbic region (PreL): 39\% increase), striatum (nucleus accumbens core (AcbC): 30\% increase; nucleus accumbens shell (AcbS): 33\% increase; caudate putamen $(\mathrm{CPu}): 46 \%$ increase), insular cortex (IC: $23 \%)$, amygdala (central amygdaloid nucleus (CeA): $26 \%$ increase; medial amygdaloid nucleus (MeA): 17\% increase; basomedial amygdaloid nucleus (BMA): 16\% increase; basolateral amygdaloid nucleus (BLA): $17 \%$ increase), and ventral hippocampus (vHippo, 94\% increase), including ventral hippocampal subregions (ventral cornus ammon (CA) regions vCA1 and vCA3, ventral dentate gyrus (vDG)). No changes of Oxtr mRNA expression were found in the infralimbic region (IL), orbitofrontal cortex (OFC), hypothalamic paraventricular nucleus (PVN), supraoptic nucleus (SON), and dorsal hippocampal subregions (dCA1, dCA3, dDG), see Figure 1a. F- and $p$-values are summarized in Supplementary Table S1. 
a

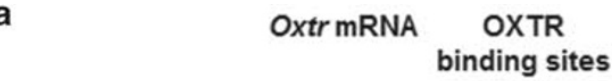

Bregma
$+2.7 \mathrm{~mm}$

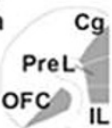

$-1.2 \mathrm{~mm}$
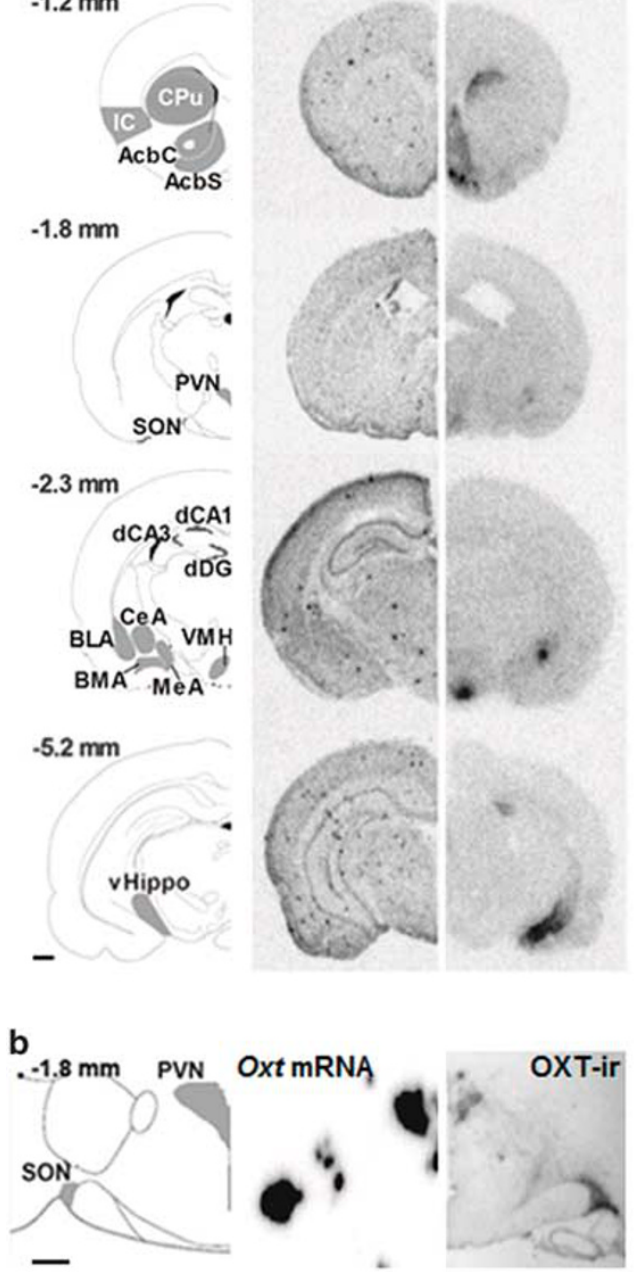

Oxtr mRNA
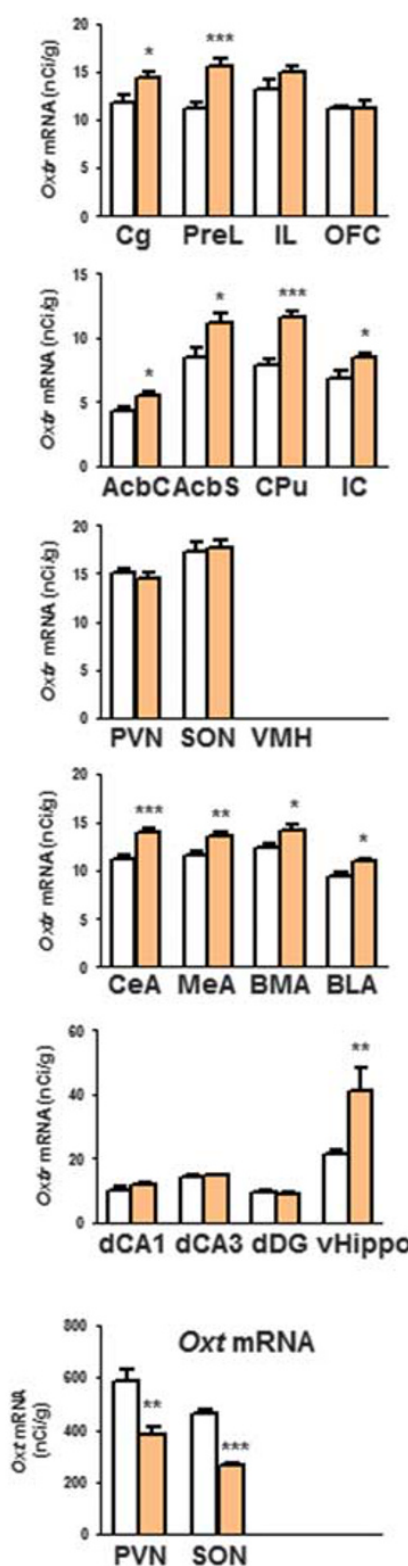

\section{OXTR binding sites}
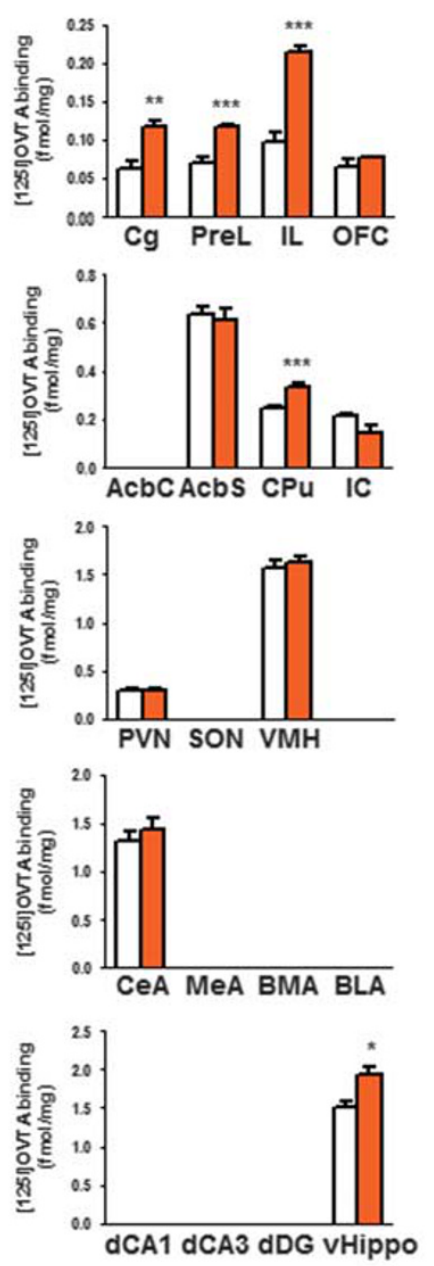

Figure I Expression of the oxytocin (OXT) system in 3 weeks abstinent rats. (a) OXT receptor (Oxtr) mRNA and OXTR binding sites are increased in several forebrain regions of dependent rats. (Left panels) Schematic outline of analyzed regions in the rat brain according to Paxinos and Watson (I998) (left). OXTR expression pattern for mRNA (in situ hybridization, middle) and binding sites ([ $\left.{ }^{i 25} \mid\right]$ OVTA receptor autoradiography, (right) corresponding to the schematic outline. (Right panels) Bar graphs showing Oxtr mRNA (left) and OXTR binding sites (right) in analyzed regions of alcohol-dependent (Alc-dep., orange bars) and -non-dependent (Non-dep., white bars) rats. Data are expressed as mean \pm SEM (nCi/g for mRNA or fmol/mg for binding sites). Statistical analysis was performed by region-wise one-way analysis of variance (ANOVA), $N=4$-8/group, $p$-values: * $p<0.05$; ** $p<0.01$; *** $p<0.00$ I. For abbreviations and experimental procedures, see Materials and Methods. (b) Reduced hypothalamic OXT expression in dependent rats. (Left panels) Schematic outline of the hypothalamic rat brain region at Bregma level - $1.8 \mathrm{~mm}$ according to Paxinos and Watson (1998) (left). OXT mRNA pattern (middle) and OXT immunoreactivity (ir, right) corresponding to the schematic outline in the PVN and the SON. (Right panels) Bar graphs showing Oxt mRNA (left) and OXT-ir cells (right) in the PVN and SON of alcohol-dependent (Alc-dep., orange bars) and -non-dependent rats (Non-dep., white bars), displayed as mean \pm SEM (Oxt mRNA: nCi/g, OXT-ir: mean grey value). OXT-ir mean grey values of non-dependent rats (PVN: mean grey value $=74.2 \pm 1.1$; SON: mean grey value $=63.0 \pm 1.0$ ) are defined as $0 \%$ and changes in density show decreased density in OXT-ir in alcohol-dependent rats (dark-orange bars). Statistical analysis was performed by region-wise one-way ANOVA, $N=7-8$ rats/group for in situ hybridization and $n=3-4$ rats/group for immunoreactivity measurements, $p$ values: * ${ }^{*}<0.05$; ** $p<0.01$; **** $<0.00 \mathrm{I}$. AcbC, nucleus accumbens core; AcbS, nucleus accumbens shell; BLA, basolateral amygdaloid nucleus; BMA, basomedial amygdaloid nucleus; CeA, central amygdaloid nucleus; Cg, cingulate cortex; CPu, caudate putamen; dCAI, dorsal hippocampal cornus ammon I subregion; dCA3, dorsal hippocampal cornus ammon 3 subregion; dDG, dorsal dentate gyrus; IC, insular cortex; IL, infralimbic region; MeA, medial amygdaloid nucleus; OFC, orbitofrontal cortex; PreL, prelimbic cortex; PVN, hypothalamic paraventricular nucleus; SON, supraoptic nucleus; vHippo, ventral hippocampus; $\mathrm{VMH}$, ventromedial hypothalamic nucleus. Scale bars I mm. 
Changes in mRNA levels translated into an increase in OXTR binding sites in the $\mathrm{Cg}$ ( $86 \%$ increase), the PreL (65\% increase), the $\mathrm{CPu}$ (38\% increase), and the vHippo (28\% increase) (Figure 1a). In the IL, there was also an increase of $117 \%$. In all other investigated regions, no changes in OXTR binding sites were found. $\mathrm{F}$ and $p$-values are summarized in Supplementary Table S2.

The receptor binding results were validated in the $\mathrm{CPu}$ and the PVN by western blotting. There was a 2.8 -fold increase of $\mathrm{OXTR} / \beta$-actin ratio in the $\mathrm{CPu}(\mathrm{F}[1,5]=6.7$, $p<0.05$; Supplementary Figure S2) and no change of OXTR/ $\beta$-actin ratio in the PVN $(\mathrm{F}[1,5]=0.2, p>0.7$; Supplementary Figure S2) compared with controls. These data show a similar regulation as described for the receptor binding sites above. Thus, using two different methodological approaches, we found an increase of both receptor binding sites and protein in protracted abstinence.

Given the increased OXTR expression in alcoholdependent rats, we next asked if the endogenous ligand OXT was also altered in dependence. Oxt mRNA expression and OXT-immunoreactive (-ir) cells were measured in the PVN and SON (Figure 1b), the principal brain regions in which OXT is produced and transported to secondary locations within and outside the brain. The Oxt mRNA and OXT-ir patterns were consistent with previous publications (Ben-Barak et al, 1985; Calcagnoli et al, 2014). A decrease in Oxt mRNA was found in both regions (PVN: $35 \%$ decrease, $\mathrm{F}[1,13]=11.9, p=0.004$; SON: $44 \%$ decrease, $\mathrm{F}[1,13]=193.6$, $p<0.001$; Figure 1b). This decrease was also supported by semiquantitative analysis of OXT, as evidenced by densitometry of immunoreactive cells (PVN: $12 \%$ decrease, $\mathrm{F}[1,5]=25.1, p=0.004 ;$ SON: $8 \%$ decrease, $\mathrm{F}[1,5]=13.2$, $p=0.015$; Figure $1 \mathrm{~b})$.

Thus, after 3 weeks of abstinence, Oxt mRNA and OXT-ir were decreased, whereas Oxtr mRNA and OXTR binding sites were increased in several brain regions.

We recently described dynamic changes of the DA system during abstinence with the same animal model (Hirth et al, 2016). Since OXTRs are located on DAergic neurons of the nucleus accumbens (Acb) (Peris et al, 2017) and OXT can modulate alcohol-induced DA release in the same region (Peters et al, 2016), we chose the Acb region to investigate the changes in Oxtr mRNA expression over time during abstinence. Rats were exposed to 7 weeks of intermittent cycles of alcohol vapor and killed at several time points afterward $(0,1,3,7$, or $21 \mathrm{~d}$ after vapor exposure) (Hansson et al, 2010; Hirth et al, 2016; Uhrig et al, 2017). There was a significant effect of Time $(\mathrm{F}[1,66]=7.7, p<0.001)$ and Treatment $\times$ Time $(F[1,66]=7.7, p<0.001)$ in the AcbC as well as in the AcbS (Time: $\mathrm{F}[1,65]=5.1, p=0.001$; Treatment $\times$ Time: $\mathrm{F}[1,65]=5.1, p=0.001)$. In both the AcbC and AcbS, Oxtr mRNA expression was significantly decreased directly after vapor exposure (0 day), when the rats were still intoxicated (BAC: $273 \pm 52 \mathrm{mg} / \mathrm{dl}$; AcbC: $38 \%$ decrease, $p=0.016$; AcbS: $46 \%$ decrease, $p=0.011$ ). After 1 day of withdrawal, Oxtr mRNA was still decreased in the AcbC (34\% decrease, $p=0.033$ ) and there was a trend toward a decrease in the AcbS (33\% decrease, $p=0.055)$. No effect was observed for both regions after 3 and 7 days of abstinence; however, after 21 days there was a significant increase in Oxtr mRNA expression (AcbC: 67\% increase, $p<0.001$; a
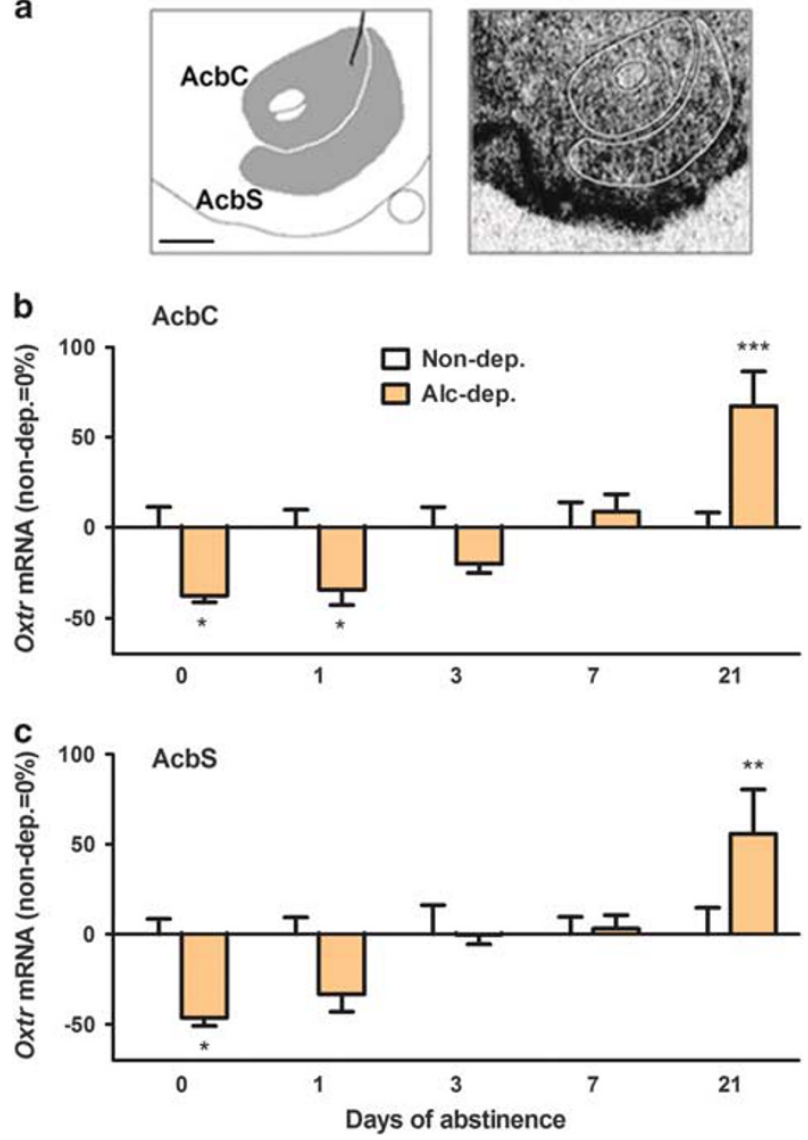

Figure 2 Oxytocin mRNA (Oxtr mRNA) is reduced in the nucleus accumbens by acute alcohol and during early withdrawal, while increased after prolonged abstinence. ( $\mathrm{a}$, left) Schematic outline of the nucleus accumbens core $(\mathrm{AcbC})$ and the nucleus accumbens shell (AcbS) according to Paxinos and Watson (1998), and Oxtr mRNA pattern in the Acb region (right). (b) Transcriptional changes in Oxtr mRNA level during various stages of abstinence in the $A c b C$ and (c) in the AcbS of dependent rats (Alc-dep., light-orange bars) and non-dependent rats (Non-dep., white bars). Bar graphs show the percentage of regulation relative to non-dependent rats. Absolute values are listed in Supplementary Table S3. Statistical analysis was performed by two-way analysis of variance (ANOVA), followed by Fisher's least significant difference (LSD) test, $N=6$-8/group, $p$-values: ${ }^{*} p<0.05$,

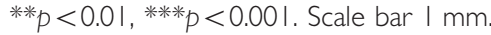

AcbS: $56 \%$ increase, $p=0.002$; Figure 2). Absolute values are listed in Supplementary Table S3.

We also investigated changes of Oxt mRNA during abstinence in the PVN and SON. No differences were found between the control groups in both regions. Therefore controls were pooled, and data were analyzed by one-way ANOVA and the respective alcohol-dependent group was compared to the pooled control group using Fisher's LSD post-hoc test. There was a significant overall treatment effect in the PVN $(\mathrm{F}[1,5]=3.1, p<0.05)$ and $\operatorname{SON}(\mathrm{F}[1,5]=3.0$, $p<0.05)$. Post-hoc analysis revealed a similar regulation of Oxt mRNA in both regions. At the end of alcohol exposure (at day 0) transcripts were decreased in the PVN by $13 \%$ $(p<0.01)$ and in the SON by $50 \%(p<0.01)$. Transcripts remained decreased during abstinence in both regions and reached significance in the PVN on day $3(14 \%, p<0.01), 7$ $(12 \%, p<0.05), 21(10 \%, p<0.05)$ and in the SON on day $21(56 \%, p<0.01)$ as compared to controls (see 


\section{Dependent rats}
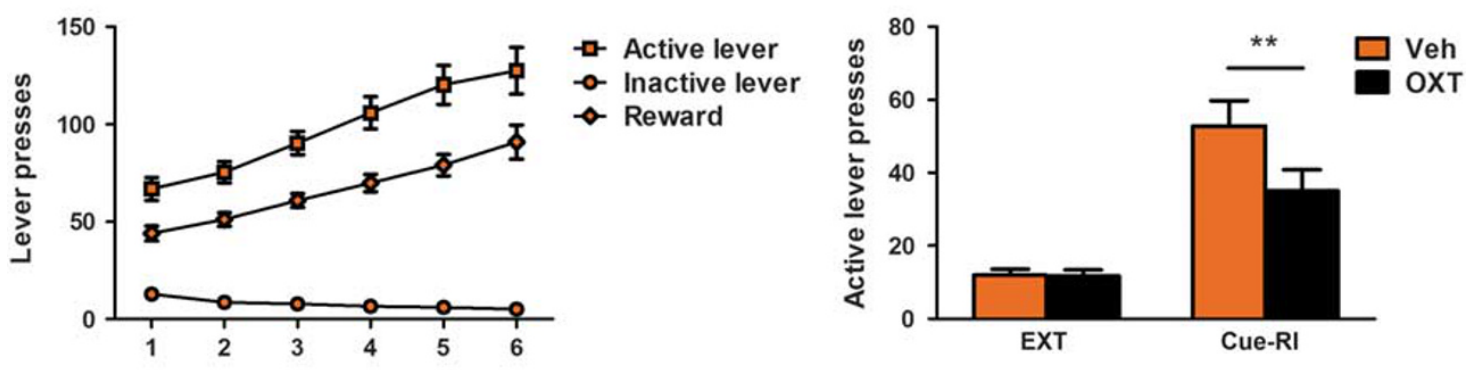

\section{Non-dependent rats}
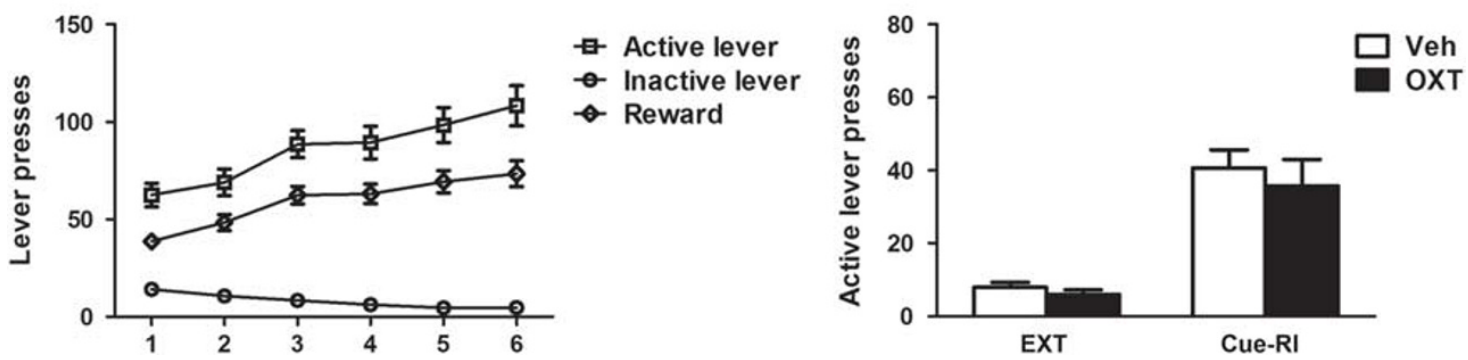

Figure 3 Cue-induced reinstatement of alcohol-seeking is decreased after intracerebroventricular (icv) administration of oxytocin (OXT) in alcoholdependent rats. (Left) Training of alcohol self-administration of rats later made dependent by alcohol vapor exposure (upper left) and non-dependent rats (lower left); displayed are active and inactive lever presses as well as number of received rewards of dependent (dark-orange color) and non-dependent rats (white color) (mean \pm SEM). (Right) Extinction (EXT) and cue-reinstatement (Cue-RI) of alcohol seeking after icv injection of IO nM OXT (black bar) or vehicle (Veh) in alcohol-dependent (upper right, Veh $=$ aCSF, dark-orange bar) and -non-dependent rats (lower right, Veh $=$ aCSF, white bar). Data are expressed as mean \pm SEM. Statistical analysis was performed by general linear model variant analysis, followed by Newman-Keuls test if appropriate, $p$-values: *** $p<0.0$ I , N = 7-I I/group. Cue-reinstatement values were significantly different compared with extinction values in all tested groups (not shown in graph), $p-$ values between groups: $* * 0.01$.

Supplementary Figure S3, absolute values are summarized in Supplementary Table S3).

Thus, there was a dynamic regulation of Oxtr mRNA during abstinence, decreased by acute alcohol and during acute withdrawal, and increased transcripts after prolonged abstinence. In contrast, hypothalamic Oxt mRNA remained decreased during abstinence.

Brain OXT decreases cue reinstatement of alcohol-seeking in alcohol dependent rats. Our expression data shows decreased OXT and increased OXTR binding sites and expression during prolonged abstinence. These expression data predict an involvement of OXT in relapse-like behavior. Therefore, we aimed to pharmacologically validate our expression data by testing the effects of OXT on cueinduced reinstatement of alcohol-seeking behavior in $21 \mathrm{~d}$ abstinent rats.

Alcohol-dependent and non-dependent rats displayed a similar acquisition of alcohol self-administration during the six weeks of training sessions (see Figure 3). During the extinction phase, both groups reduced their active lever pressing to $<10 \%$ of the previous baseline in a similar manner (Figure 3). Cue-induced reinstatement of alcoholseeking behavior was then tested after intracerebroventricular injection of OXT. The effect of the OXT dose $(10 \mathrm{nM}$ intracerebroventricular) was tested during reinstatement testing. The drug was injected directly before the start of the session. In alcohol-dependent rats, both groups displayed a significant reinstatement behavior $(\mathrm{F}[1,16]=42.45$, $p<0.0001)$, but rats treated with OXT showed a significantly decreased active lever pressing compared to the control group $(p=0.002$, Figure 3$)$. Non-dependent rats equally showed significant reinstatement behavior $(\mathrm{F}[1,17]=56.85$, $p<0.001)$. Contrary to alcohol-dependent rats, OXT administration did not have an effect on the reinstatement response in non-dependent rats (Figure 3).

\section{Human Studies}

Increased OXTR expression and binding sites in human alcoholics. To translationally validate these data in rats, we next examined OXTR expression analysis in post-mortem brain samples of human alcoholics, and performed a clinical pilot study on the effects of OXT on alcohol cue-reactivity in heavy social drinkers.

We analyzed changes on OXTR expression at both transcriptional (by qRT-PCR) and receptor binding (by OXTR autoradiography) levels, in a well-characterized brain tissue sample set of deceased alcoholics (Meinhardt et al, 2013; Hirth et al, 2016; Hermann et al, 2017). Alcoholics consumed more than $80 \mathrm{~g}$ alcohol per day, whereas control subjects had an average of $<20 \mathrm{~g}$. Subjects were free of detectable blood alcohol at their time of death and there were no significant difference in age, post-mortem interval, or brain $\mathrm{pH}$ between the groups (see Supplementary Tables S4 and S5). These factors were included into region-wise general linear models (GLMs) for OXTR mRNA or binding (summarized in Supplementary Table S6). The analyses revealed significantly increased OXTR binding sites as assessed by $\left[{ }^{125} \mathrm{I}\right] \mathrm{OVTA}$ binding in all investigated regions (anterior cingulate cortex (ACC): 241\% increase; dorsolateral 
prefrontal cortex, Brodmann area 9 (BA9): 190\% increase; ventral striatum (VS): 67\% increase; NC: $94 \%$ increase; Figure 4 and Supplementary Table S6). Correspondingly, GLMs for qRT-PCR showed increased OXTR mRNA levels in BA9, VS, and NC, and no change in OXTR mRNA in ACC (Figure 4 and Supplementary Table S6). Thus in deceased human alcoholics and prolonged abstinent dependent rats, OXTR expression increases at both the mRNA and protein levels.

It has previously been shown that the commonly used radioligand $\left[{ }^{125} \mathrm{I}\right] \mathrm{OVTA}$ does not bind selectively to the OXTR, but also to the vasopressin V1a receptor and possibly other non-peptide receptors (Toloczko et al, 1997; Freeman et al, 2014a, b). We therefore investigated $A V P R 1 A$ and $A V P R 1 B$ mRNA expression in the BA9 region of deceased alcoholics and controls by qRT-PCR (see Supplementary Tables S4). We did not find any significant changes in alcoholic patients $(A V P R 1 A: \quad \mathrm{F}[1,23]=0.04 ; \quad p=0.85$; $A$ VPR1B: $\mathrm{F}[1,20]=2.74 ; p=0.11)$. This supports the specificity of increased OXTR binding in deceased alcoholics.

OXT reduces neural reactivity to alcohol-related cues in heavy social drinkers. Finally, we performed a pilot clinical trial (German clinical trial number DRKS00009253; URL: https://drks-neu.uniklinik-freiburg.de/drks_web) to examine whether IN OXT (24 IU) could reduce neural reactivity to alcohol-related cues in human subjects. We recruited 15 male subjects who were non-treatment-seeking heavy social drinkers (Supplementary Figure S4; for sample description and information on severity of dependence and drinkingrelated psychometric variables, see Supplementary Information). On average these participants were $33( \pm 16)$ years old. They consumed $2.86( \pm 1.80)$ standard drinks of alcohol $( \pm 12 \mathrm{~g})$ per day, that is, an average of $34( \pm 22) \mathrm{g}$ of alcohol per day. We performed fMRI on these subjects while they participated in a neural cue-reactivity test, which is a sensitive proxy measure of alcohol-seeking behavior (Jorde et al, 2014; Courtney et al, 2016; Noori et al, 2016).

Figure 5a displays examples of the pictorial stimuli and illustrates the fMRI block design. fMRI data of 12/15 heavy social drinkers were available for both conditions (OXT and placebo). The main effects of the contrast alcohol $v s$ neutral cues for the OXT and placebo conditions are listed in Supplementary Tables S8 and S9. Comparing the neural activation during the OXT with the placebo conditions suggested that cue-reactivity was significantly decreased by OXT in the IC, the hippocampal/parahippocampal formation, the $\mathrm{Cg}$, the inferior and the medial frontal gyrus, and in visual and motor regions (Figure 5 and Table 1 ). There was no significant increase in cue-reactivity in any brain region in the OXT condition.

\section{DISCUSSION}

Here we provide evidence that OXT can act as a therapeutic candidate for alcohol use disorder, with promising results from three studies: analysis of an animal model of alcoholism, human post-mortem brain tissue, and supportive pilot data in heavy social drinkers. We found increased OXTR mRNA and OXTR protein levels in frontal and striatal brain areas in 3 weeks abstinent alcohol-dependent rats. Additionally, these rats showed a reduction of Oxt mRNA
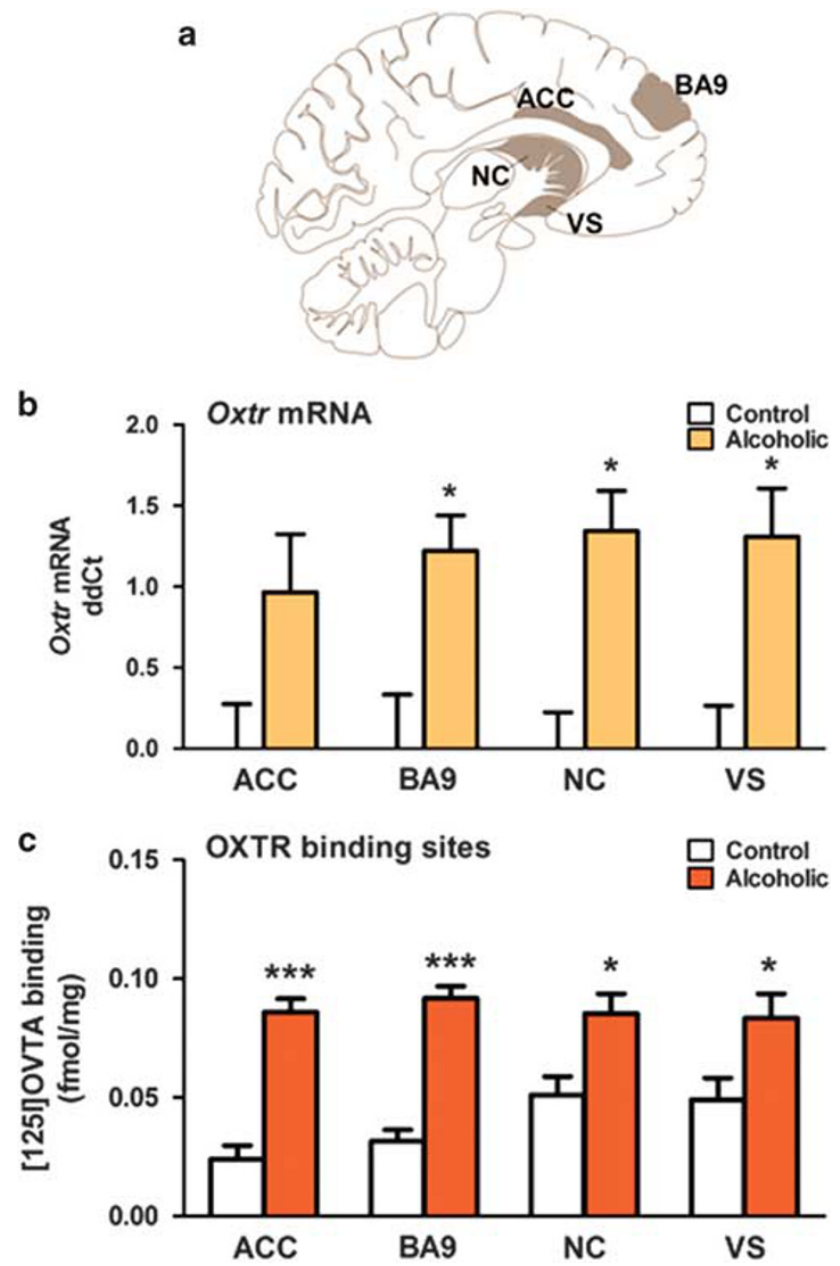

Figure 4 Increased oxytocin mRNA (OXTR mRNA) and OXTR binding sites in post-mortem samples of alcoholics compared with control samples. (a) Schematic outline of analyzed regions in the human brain according to von Hagens et al (1990). (b) OXTR mRNA expression and (c) [ I 251]OVTA binding; bar graphs illustrate quantitative analysis in post-mortem samples of alcoholics (OXTR mRNA: light orange bars; OXTR binding sites: dark-orange bars) and age-matched controls (white bars). Data are shown as mean \pm SEM (ddCt for mRNA expression, dCt values for controls are as follows: anterior cingulate cortex (ACC): II.13 0.2 ; Brodmann area 9 (BA9): II.14 \pm 0.3 ; nucleus caudatus (NC): $9.80 \pm 0.2$; ventral striatum (VS): $9.28 \pm 0.3 ;$ fmol/mg for binding sites). Statistical analysis was performed by region-wise general linear models (GLMs), accounting for the possible influence of age, brain $\mathrm{pH}$, post-mortem interval (PMI), and smoking; $\mathrm{N}=9-$ I5/group, $p$-values: $* p<0.05$; *** $p<0.01$; $* * * *<0.001$, see also Supplementary Table S6.

and OXT protein expression in hypothalamic nuclei, which provide the major source of OXT. Pharmacological validation showed that central administration of OXT reduced cueinduced reinstatement of alcohol-seeking in dependent rats, but not in non-dependent rats. We found increased OXTR mRNA and OXTR protein levels in frontal and striatal brain areas of human alcoholics, demonstrating the translational value of our results in rats. Finally, a clinical pilot fMRI study in heavy social drinkers revealed that OXT decreased neural cue-reactivity in similar brain networks as those implicated in dependent humans and rats.

OXT has been in the focus of preclinical addiction research, with findings of exogenous OXT decreasing the 
a

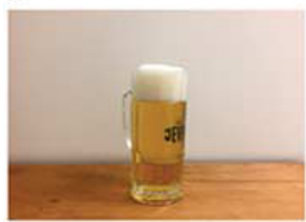

18 alcohol blocks

(5 alcohol stimuli per block, 4 seconds each)

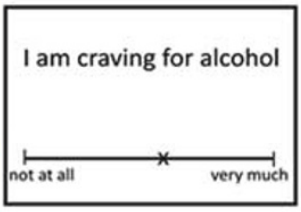

craving rating and fixation cross: altogether 20 seconds

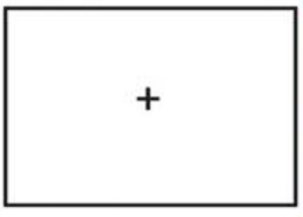

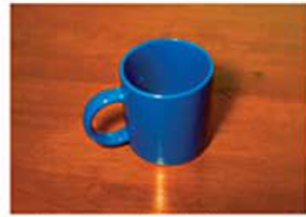

12 neutral blocks ( 5 neutral stimuli per block, 4 seconds each)

b
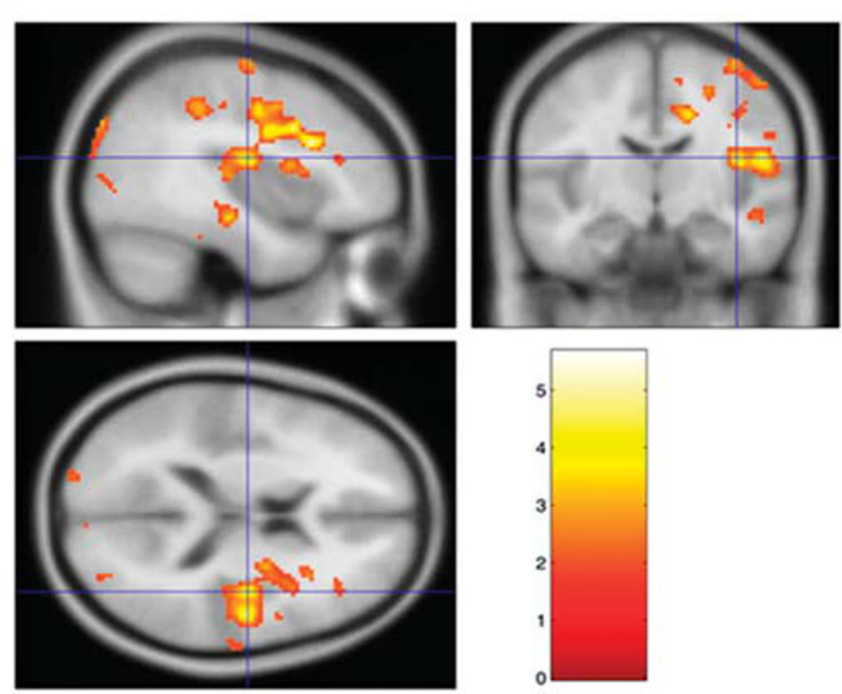

Figure 5 Oxytocin (OXT) reduces neural reactivity to alcohol-related cues in heavy social drinkers. (a) Cue-reactivity task (alcohol, neutral pictures). (b) Decrease in blood oxygenation level-dependent (BOLD) response to alcohol compared with neutral cues by oxytocin compared to placebo in heavy social drinkers, $N=12, p<0.05$ family-wise error rate (FWE)-corrected (Monte Carlo-based simulations), $(x, y, z)=(40,-12,16)$, effect size in sphere of I $\mathrm{cm}$ diameter: 0.37. The neutral pictures were taken from the International Affective Picture System (IAPS; Lang et al, 2008).

Table I Decrease in BOLD Response of Alcohol Cue-Reactivity by Oxytocin

\begin{tabular}{|c|c|c|c|c|c|c|c|c|}
\hline \multirow{2}{*}{$\begin{array}{l}\text { Side } \\
\text { Right }\end{array}$} & \multirow{2}{*}{$\begin{array}{c}\text { Lobe } \\
\text { Frontal lobe }\end{array}$} & \multirow{2}{*}{$\begin{array}{c}\text { Brain areas } \\
\text { Precentral gyrus/middle frontal gyrus/inferior frontal gyrus }\end{array}$} & \multirow{2}{*}{$\frac{\text { Brodmann area }}{6}$} & \multirow{2}{*}{$\begin{array}{c}\text { Cluster size } \\
3231\end{array}$} & \multicolumn{3}{|c|}{$\begin{array}{c}\text { MNI } \\
\text { coordinates }\end{array}$} & \multirow{2}{*}{$\frac{t_{\text {maximum }}}{5.66}$} \\
\hline & & & & & 30 & -4 & 34 & \\
\hline Right & Limbic lobe & Cingulate gyrus/hippocampus/parahippocampal gyrus & & & & & & \\
\hline Right & Occipital lobe & Cuneus/superior occipital gyrus/middle occipital gyrus & 19 & 1557 & 32 & -78 & 22 & 4.28 \\
\hline Left & Occipital lobe & Cuneus/superior occipital gyrus & 19 & & & & & \\
\hline
\end{tabular}

Abbreviations: BOLD, blood oxygenation level-dependent; FWE, family-wise error rate; MNI, Montreal Neurological Institute.

Brain areas with decreased BOLD response (alcohol compared with neutral cues) by oxytocin compared to placebo in heavy social drinkers $(n=12$ ), $p<0.05 \mathrm{FWE}$ corrected (Monte Carlo-based simulations).

consumption of several drugs including methamphetamines, heroin, cocaine, and alcohol (Kovacs et al, 1998; Qi et al, 2009; Carson et al, 2010; Bowen et al, 2011; Peters et al, 2013; Lee et al, 2016; Leong et al, 2016; MacFadyen et al, 2016;
Peters et al, 2016; King et al, 2017). Concerning alcohol, most of the reports suggest a potential role of OXT as a therapeutic target (Lee et al, 2016). However, to our knowledge so far no study has been done in alcohol-dependent rats, that is, in an 
animal model with alcohol-induced long-term neuroadaptations comparable to those in humans. Here, we used postdependent rats-a well-characterized and widely accepted animal model with predictive validity and utility for medication development in alcoholism (Meinhardt and Sommer, 2015).

Intracerebroventricular-administered OXT decreased cuereinstatement in dependent, but not in non-dependent rats. Many compounds tested so far are not specific for alcoholdependent subjects (Meinhardt and Sommer, 2015), although several systems appear to be additionally recruited in alcohol dependence, including stress systems such as the corticotropin-releasing hormone system in the amygdala (Hansson et al, 2006, 2007; Sommer et al, 2008), as well as dynorphin (Walker et al, 2011) or vasopressin (Edwards et al, 2012). This might suggest that in alcohol dependence, the OXT system is particularly involved in and sensitized to processes mediating alcohol-seeking behavior. Thus, OXT represents a promising target for treatment development, because it would selectively affect patients with an OXT deficiency.

A striking feature of the present study is the high level of concordance in the alterations of OXTRs in alcoholdependent humans and rats. These relations support the validity of this pathophysiological mechanism for alcohol dependence as well as the translational value of this animal model. We found increased OXTR mRNA and binding levels in striatal and prefrontocortical post-mortem samples from alcohol-dependent subjects of both species. The animal model provides important additional information about the time course of dependence-induced neuroadaptation of the OXT system. First, OXTRs undergo important changes upon cessation of alcohol exposure, being downregulated during alcohol intoxication and early withdrawal before a robust upregulation after a few weeks. Similar dynamic regulation has been found in the dopamine system of dependent rats during abstinence (Hirth et al, 2016). A possible link for this similar dynamical regulation of the OXT and dopamine systems has been recently provided by the finding that intracerebroventricular OXT prevents alcohol-evoked dopamine release in the Acb (Peters et al, 2016). It also suggests different mechanisms to be involved in the actions of OXT on acute alcohol withdrawal (Pedersen et al, 2013) compared with the decreased alcohol cue-reactivity reported here.

A second important finding from our animal study is that the changes in OXTR expression are widespread and region specific. Increases were not restricted to the striatum and the prefrontal cortex but also included amygdala and hippocampal regions. Interestingly, OXTRs in hypothalamic regions seemed unaffected. In the PVN and SON of dependent rats, we instead found a persistent decrease of OXT. This may be due to a loss of hypothalamic OXT neurons (Silva et al, 2002; Stevenson et al, 2017) and thus may explain why OXT treatment is effective at acute (Pedersen et al, 2013) and protracted abstinence. The findings agree with severe morphological changes in OXT neurons of hypothalamic nuclei and decrease of OXT immunoreactivity in the SON and the posterior pituitary lobe from human patients afflicted with chronic alcoholic disease (Sivukhina et al, 2006). The mechanisms underlying the dynamic changes of the receptor during abstinence remain unknown.
There are obvious mismatches of OXTR at mRNA and protein expression (eg, dorsal hippocampal neurons contain high levels of Oxtr mRNA with no or too low detectable amount of OXTR binding signal). One explanation may be that after synthesis the OXTR protein is transported along the axons and/or into distal dendrites at a different brain site (Peris et al, 2017). On the contrary, Mitre et al (2016) and Yoshida et al (2009) demonstrate a widespread expression of OXTR in different forebrain regions (including the dorsal hippocampus) using an immunohistochemistry and a transgenic reporter line approach, respectively. Thus, the observed mismatches of mRNA and receptor binding sites may be due to methodological issues.

In line with our observations, increased OXTR and decreased OXT levels were also observed after long-term cocaine, morphine, and methamphetamine administration (Sarnyai and Kovacs, 1994; You et al, 2000; Zanos et al, 2014a, b; Georgiou et al, 2015; Lee et al, 2016), and might reflect an adaptive reaction within the OXT target regions to decreased peptide expression upon chronic drug exposure. Therefore, supplementing OXT should positively affect drugrelated behaviors, which has been demonstrated here for alcohol cue-reactivity in abstinent rats.

Alcohol cue-reactivity may also be affected by supplementing OXT in heavy social drinkers. Our pilot study in humans showed that a single intranasal dose (24 IU) OXT decreased neural cue-reactivity in brains regions implicated by our analysis of receptor expression in rats and deceased humans. Reduced alcohol cue-reactivity was also found in regions relevant for craving (eg, IC). The decrease of neural activation might suggest a decline of the anticipation of alcohol cues by OXT.

Intranasal OXT has been proposed as a treatment for many different conditions, including schizophrenia (Woolley et al, 2014; Rich and Caldwell, 2015), autism spectrum disorders (Okamoto et al, 2016), and substance dependence (McRae-Clark et al, 2013; Kirkpatrick et al, 2014; Lee et al, 2014; Flanagan et al, 2015; Woolley et al, 2016). A recent study investigated the effect of intranasal OXT on social perception, craving, and approach behavior in alcohol use disorder (Mitchell et al, 2016). While these authors did not find a significant effect on cue-induced craving between groups, OXT appeared to differentially influence subjects depending on their level of attachment anxiety. In another small study, intranasal OXT was effective in reducing alcohol withdrawal symptoms in alcohol-dependent subjects (Pedersen et al, 2013).

Recent studies by Quintana et al $(2015,2017)$ assessed the effects of a single dose of OXT (IN, 24 IU) on plasma levels up to $2 \mathrm{~h}$ after treatment and suggested a direct nose-to-brain transport with the IN delivery mechanism. The IN OXT administration seems to achieve therapeutic benefit, while minimizing adverse effects due to peripheral OXTR activation (Bales et al, 2007; Bales et al, 2013). Overall, these findings combined with our results certainly warrant further preclinical and clinical investigation of this treatment possibility, especially since intranasal OXT has been shown to be safely tolerated by the subjects.

The present study has the following limitations. First, the radioligand, $\left[{ }^{125} \mathrm{I}\right] \mathrm{OVTA}$, has been used before for OXTR autoradiography in rodents and humans (Liberzon et al, 1994; Liberzon and Young, 1997; Olazabal and Young, 2016a,b; 
Uhrig et al, 2016). However, some studies on non-human primates suggest significant binding to other nonapeptide receptors, most notably vasopressin 1a receptors (Toloczko et al, 1997; Freeman et al, 2014a, b). Given that we found no differences between alcoholic patients and controls in $A V P R 1 A$ and $A V P R 1 B$ mRNA levels, we attribute the observed differences in ligand binding to the effects on OXTR. Transcriptional levels do not universally reflect protein levels, but for OXTR we found a high concordance between these levels of assessment. Important to mention is that the selective OXTR antagonist ALS-II-69 has been recently used for competitive binding assays (Freeman et al, 2014b, 2017), although this compound is currently not commercially available. Second, the difference in responding under reinstatement is quite small between dependent and non-dependent groups. Examination of several OXT doses might better show potential differences in responses. Thus, the usage of a single dose of OXT represents a limitation of the study. Third, the sample size of the human pilot study is low and the fMRI results did not show a cue-induced activation in striatal regions. In a previous study (VollstädtKlein et al, 2010) using the same paradigm as here we found increased ventral striatal activation in light drinkers and more dorsal striatal activation in heavy drinkers. With regard to measures of severity of dependence (see sample description in Supplementary Information), the participants of the present study are ranging between light social drinkers and already dependent heavy social drinkers, and thus might be the reason why we neither found a ventral nor a dorsal striatal activation. Furthermore, the use of a lower dose of IN OXT (8 IU) may be more efficacious than the higher dose used in this study, at least for single administration trials (Quintana et al, 2017). Nevertheless, the results from the present fMRI study are in line with other independent experiments in humans and rats, but should be confirmed in a larger cohort. Fourth, only male subjects participated in the studies. This is justified by the fact that alcohol use disorders are much more prevalent in males. Nevertheless, also females are affected, and for generalization of the present results, studies in both sexes will be required. Finally, there was no direct assessment of the agonal state available by the provider of the postmortem tissues, the New South Wales Tissue Resource Centre (University of Sydney, Australia). However, tissues from this brain bank were of good quality and have been already successfully used in numerous studies (Sheedy et al, 2008; Meinhardt et al, 2013; Hirth et al, 2016; Hermann et al, 2017).

In conclusion, we here show an increase in OXTR expression (mRNA and binding sites) both in alcoholic patients and alcohol-dependent rats, as well as a decrease in Oxt mRNA and OXT peptide in alcohol-dependent rats. Furthermore, we could demonstrate that OXT decreased alcohol cue-reactivity in rats at the behavioral level by the cue-induced reinstatement test and in heavy social drinkers upon cue exposure at the neural level. The activity differences found in the human fMRI task, although preliminary, comprised similar brain networks as found in the mechanistic postmortem studies. Our highly translational, multilevel approach underlines the importance of the OXT system in alcohol dependence and supports current efforts made to understand the underlying mechanism and potential treatment applications for this disorder.

\section{FUNDING AND DISCLOSURE}

The authors declare no conflict of interest.

\section{ACKNOWLEDGMENTS}

We are very grateful for obtaining the brain samples from the Sydney Brain Bank, especially for Clive Harper, Donna Sheedy, and Jillian J Kril. We thank Elisabeth Röbel, Marvin Pätz, Sabrina Koch, and Michael Rieß for their technical support and their assistance in data collection. Further, we thank Sarah Gerhardt and Sabine Hoffmann for their assistance with data management and preparation. Our work is supported by the Bundesministerium für Bildung und Forschung (e:Med program, FKZ: 01ZX1311A (Spanagel et $a l, 2013$ ) and AERIAL, $01 \mathrm{EE} 1406 \mathrm{C})$, the Deutsche Forschungsgemeinschaft (SFB1134, DFG HA6102/1-1), and European Union's Horizon2020 research and innovation program (668863, SyBil-AA).

\section{AUTHOR CONTRIBUTIONS}

$\mathrm{ACH}, \mathrm{RS}, \mathrm{WHS}, \mathrm{VG}$, and RC were responsible for study design of the rat and post-mortem brain study and procured study funding. SU performed post-mortem experiments. SU, WHS, and ACH analyzed post-mortem data. SU and ED performed behavioral animal experiments. SU, EK, and VG performed expression experiment in rats. RCF provided OXTR-2 antibodies for western blots. SU, WHS, ACH, and $\mathrm{RS}$ analyzed rat data. SV-K, AK, and FK were responsible for the concept and design of the fMRI study, and FK procured funding. SB and AK performed clinical experiments. SV-K analyzed the fMRI data. SU, WHS, SV-K, RS, and ACH drafted the manuscript. All authors revised the manuscript critically for important intellectual content and approved the final version.

\section{REFERENCES}

Bales KL, Perkeybile AM, Conley OG, Lee MH, Guoynes CD, Downing GM et al (2013). Chronic intranasal oxytocin causes long-term impairments in partner preference formation in male prairie voles. Biol Psychiatry 74: 180-188.

Bales KL, van Westerhuyzen JA, Lewis-Reese AD, Grotte ND, Lanter JA, Carter CS (2007). Oxytocin has dose-dependent developmental effects on pair-bonding and alloparental care in female prairie voles. Horm Behav 52: 274-279.

Ben-Barak Y, Russell JT, Whitnall MH, Ozato K, Gainer H (1985). Neurophysin in the hypothalamo-neurohypophysial system. I. Production and characterization of monoclonal antibodies. J Neurosci 5: 81-97.

Bethlehem RA, van Honk J, Auyeung B, Baron-Cohen S (2013). Oxytocin, brain physiology, and functional connectivity: a review of intranasal oxytocin fMRI studies. Psychoneuroendocrinology 38: $962-974$.

Bowen MT, Carson DS, Spiro A, Arnold JC, McGregor IS (2011). Adolescent oxytocin exposure causes persistent reductions in anxiety and alcohol consumption and enhances sociability in rats. PLOS ONE 6: e27237.

Bowen MT, Peters ST, Absalom N, Chebib M, Neumann ID, McGregor IS (2015). Oxytocin prevents ethanol actions at delta subunit-containing GABAA receptors and attenuates ethanolinduced motor impairment in rats. Proc Natl Acad Sci USA 112: 3104-3109. 
Calcagnoli F, de Boer SF, Beiderbeck DI, Althaus M, Koolhaas JM, Neumann ID (2014). Local oxytocin expression and oxytocin receptor binding in the male rat brain is associated with aggressiveness. Behav Brain Res 261: 315-322.

Carson DS, Cornish JL, Guastella AJ, Hunt GE, McGregor IS (2010). Oxytocin decreases methamphetamine self-administration, methamphetamine hyperactivity, and relapse to methamphetamine-seeking behaviour in rats. Neuropharmacology 58: 38-43.

Courtney KE, Schacht JP, Hutchison K, Roche DJ, Ray LA (2016). Neural substrates of cue reactivity: association with treatment outcomes and relapse. Addict Biol 21: 3-22.

Edwards S, Guerrero M, Ghoneim OM, Roberts E, Koob GF (2012). Evidence that vasopressin $\mathrm{V} 1 \mathrm{~b}$ receptors mediate the transition to excessive drinking in ethanol-dependent rats. Addict Biol 17: 76-85.

Flanagan JC, Baker NL, McRae-Clark AL, Brady KT, Moran-Santa Maria MM (2015). Effects of adverse childhood experiences on the association between intranasal oxytocin and social stress reactivity among individuals with cocaine dependence. Psychiatry Res 229: 94-100.

Freeman SM, Inoue $\mathrm{K}$, Smith AL, Goodman MM, Young LJ (2014a). The neuroanatomical distribution of oxytocin receptor binding and mRNA in the male rhesus macaque (Macaca mulatta). Psychoneuroendocrinology 45: 128-141.

Freeman SM, Smith AL, Goodman MM, Bales KL (2017). Selective localization of oxytocin receptors and vasopressin 1a receptors in the human brainstem. Soc Neurosci 12: 113-123.

Freeman SM, Walum H, Inoue K, Smith AL, Goodman MM, Bales KL et al (2014b). Neuroanatomical distribution of oxytocin and vasopressin 1a receptors in the socially monogamous coppery titi monkey (Callicebus cupreus). Neuroscience 273: 12-23.

Georgiou P, Zanos P, Ehteramyan M, Hourani S, Kitchen I, Maldonado $\mathrm{R}$ et al (2015). Differential regulation of mGlu5 R and $\mathrm{MuOPr}$ by priming- and cue-induced reinstatement of cocaineseeking behaviour in mice. Addict Biol 20: 902-912.

Grinevich V, Knobloch-Bollmann HS, Eliava M, Busnelli M, Chini B (2016). Assembling the puzzle: pathways of oxytocin signaling in the brain. Biol Psychiatry 79: 155-164.

Grüsser SM, Wrase J, Klein S, Hermann D, Smolka MN, Ruf M et al (2004). Cue-induced activation of the striatum and medial prefrontal cortex predicts relapse in abstinent alcoholics. Psychopharmacology (Berl.) 175: 296-302.

Hansson AC, Cippitelli A, Sommer WH, Ciccocioppo R, Heilig M (2007). Region-specific down-regulation of Crhrl gene expression in alcohol-preferring msP rats following ad lib access to alcohol. Addict Biol 12: 30-34.

Hansson AC, Cippitelli A, Sommer WH, Fedeli A, Bjork K, Soverchia $\mathrm{L}$ et al (2006). Variation at the rat Crhrl locus and sensitivity to relapse into alcohol seeking induced by environmental stress. Proc Natl Acad Sci USA 103: 15236-15241.

Hansson AC, Nixon K, Rimondini R, Damadzic R, Sommer WH, Eskay $\mathrm{R}$ et al (2010). Long-term suppression of forebrain neurogenesis and loss of neuronal progenitor cells following prolonged alcohol dependence in rats. Int J Neuropsychopharmacol 13: 583-593.

Heilig M, Egli M, Crabbe JC, Becker HC (2010). Acute withdrawal, protracted abstinence and negative affect in alcoholism: are they linked? Addict Biol 15: 169-184.

Heilig M, Koob GF (2007). A key role for corticotropin-releasing factor in alcohol dependence. Trends Neurosci 30: 399-406.

Hermann D, Hirth N, Reimold M, Batra A, Smolka MN, Hoffmann $S$ et al (2017). Low mu-opioid receptor status in alcohol dependence identified by combined positron emission tomography and post-mortem brain analysis. Neuropsychopharmacology 42: 606-614.

Hermann D, Weber-Fahr W, Sartorius A, Hoerst M, Frischknecht $\mathrm{U}$, Tunc-Skarka $\mathrm{N}$ et al (2012). Translational magnetic resonance spectroscopy reveals excessive central glutamate levels during alcohol withdrawal in humans and rats. Biol Psychiatry 71: 1015-1021.

Hirth N, Meinhardt MW, Noori HR, Salgado H, Torres-Ramirez O, Uhrig S et al (2016). Convergent evidence from alcoholdependent humans and rats for a hyperdopaminergic state in protracted abstinence. Proc Natl Acad Sci USA 113: 3024-3029.

Jorde A, Bach P, Witt SH, Becker K, Reinhard I, Vollstadt-Klein S et al (2014). Genetic variation in the atrial natriuretic peptide transcription factor GATA4 modulates amygdala responsiveness in alcohol dependence. Biol Psychiatry 75: 790-797.

King CE, Griffin WC, Luderman LN, Kates MM, McGinty JF, Becker HC (2017). Oxytocin reduces ethanol self-administration in mice. Alcohol Clin Exp Res 41: 955-964.

Kirkpatrick MG, Lee R, Wardle MC, Jacob S, de Wit H (2014). Effects of MDMA and Intranasal oxytocin on social and emotional processing. Neuropsychopharmacology 39: 1654-1663.

Koob GF, Volkow ND (2010). Neurocircuitry of addiction. Neuropsychopharmacology 35: 217-238.

Kovacs GL, Sarnyai Z, Szabo G (1998). Oxytocin and addiction: a review. Psychoneuroendocrinology 23: 945-962.

Lang PJ, Bradley MM, Cuthbert BN (2008). International affective picture system (IAPS): Affective ratings of pictures and instruction manual. Technical Report A-8. University of Florida, Gainesville, FL.

Lee MR, Glassman M, King-Casas B, Kelly DL, Stein EA, Schroeder J et al (2014). Complexity of oxytocins effects in a chronic cocaine dependent population. Eur Neuropsychopharmacol 24: 1483-1491.

Lee MR, Rohn MC, Tanda G, Leggio L (2016). Targeting the oxytocin system to treat addictive disorders: rationale and progress to date. CNS Drugs 30: 109-123.

Leong KC, Zhou L, Ghee SM, See RE, Reichel CM (2016). Oxytocin decreases cocaine taking, cocaine seeking, and locomotor activity in female rats. Exp Clin Psychopharmacol 24: 55-64.

Liberzon I, Chalmers DT, Mansour A, Lopez JF, Watson SJ, Young EA (1994). Glucocorticoid regulation of hippocampal oxytocin receptor binding. Brain Res 650: 317-322.

Liberzon I, Young EA (1997). Effects of stress and glucocorticoids on CNS oxytocin receptor binding. Psychoneuroendocrinology 22: 411-422.

Litten RZ, Egli M, Heilig M, Cui C, Fertig JB, Ryan ML et al (2012). Medications development to treat alcohol dependence: a vision for the next decade. Addict Biol 17: 513-527.

MacFadyen K, Loveless R, DeLucca B, Wardley K, Deogan S, Thomas $\mathrm{C}$ et al (2016). Peripheral oxytocin administration reduces ethanol consumption in rats. Pharmacol Biochem Behav 140: $27-32$.

McRae-Clark AL, Baker NL, Maria MM, Brady KT (2013). Effect of oxytocin on craving and stress response in marijuana-dependent individuals: a pilot study. Psychopharmacology (Berl) 228: 623-631.

Meinhardt MW, Hansson AC, Perreau-Lenz S, Bauder-Wenz C, Stahlin O, Heilig M et al (2013). Rescue of infralimbic mGluR2 deficit restores control over drug-seeking behavior in alcohol dependence. J Neurosci 33: 2794-2806.

Meinhardt MW, Sommer WH (2015). Postdependent state in rats as a model for medication development in alcoholism. Addict Biol 20: $1-21$.

Meyer-Lindenberg A, Domes G, Kirsch P, Heinrichs M (2011). Oxytocin and vasopressin in the human brain: social neuropeptides for translational medicine. Nat Rev Neurosci 12: 524-538.

Mitchell JM, Arcuni PA, Weinstein D, Woolley JD (2016). Intranasal oxytocin selectively modulates social perception, craving, and approach behavior in subjects with alcohol use disorder. J Addict Med 10: 182-189.

Mitre M, Marlin BJ, Schiavo JK, Morina E, Norden SE, Hackett TA et al (2016). A distributed network for social cognition enriched for oxytocin receptors. J Neurosci 36: 2517-2535. 
Neumann ID, Landgraf R (2012). Balance of brain oxytocin and vasopressin: implications for anxiety, depression, and social behaviors. Trends Neurosci 35: 649-659.

Noori HR, Cosa Linan A, Spanagel R (2016). Largely overlapping neuronal substrates of reactivity to drug, gambling, food and sexual cues: a comprehensive meta-analysis. Eur Neuropsychopharmacol 26: 1419-1430.

Noori HR, Spanagel R, Hansson AC (2012). Neurocircuitry for modeling drug effects. Addict Biol 17: 827-864.

Okamoto Y, Ishitobi M, Wada Y, Kosaka H (2016). The potential of nasal oxytocin administration for remediation of autism spectrum disorders. CNS Neurol Disord Drug Targets 15: 564-577.

Olazabal DE, Young LJ (2006a). Oxytocin receptors in the nucleus accumbens facilitate 'spontaneous' maternal behavior in adult female prairie voles. Neuroscience 141: 559-568.

Olazabal DE, Young LJ (2006b). Species and individual differences in juvenile female alloparental care are associated with oxytocin receptor density in the striatum and the lateral septum. Horm Behav 49: 681-687.

Paxinos G, Watson C (1998). The Rat Brain in Stereotaxic Coordinates. Academic Press: New York, NY.

Pedersen CA, Smedley KL, Leserman J, Jarskog LF, Rau SW, Kampov-Polevoi A et al (2013). Intranasal oxytocin blocks alcohol withdrawal in human subjects. Alcohol Clin Exp Res 37: 484-489.

Peris J, MacFadyen K, Smith JA, de Kloet AD, Wang L, Krause EG (2017). Oxytocin receptors are expressed on dopamine and glutamate neurons in the mouse ventral tegmental area that project to nucleus accumbens and other mesolimbic targets. $J$ Comp Neurol 525: 1094-1108.

Peters S, Slattery DA, Flor PJ, Neumann ID, Reber SO (2013). Differential effects of baclofen and oxytocin on the increased ethanol consumption following chronic psychosocial stress in mice. Addict Biol 18: 66-77.

Peters ST, Bowen MT, Bohrer K, McGregor IS, Neumann ID (2016). Oxytocin inhibits ethanol consumption and ethanolinduced dopamine release in the nucleus accumbens. Addict Biol 22: 702-711.

Qi J, Yang JY, Wang F, Zhao YN, Song M, Wu CF (2009). Effects of oxytocin on methamphetamine-induced conditioned place preference and the possible role of glutamatergic neurotransmission in the medial prefrontal cortex of mice in reinstatement. Neuropharmacology 56: 856-865.

Quintana DS, Westlye LT, Hope S, Naerland T, Elvsashagen T, Dorum E et al (2017). Dose-dependent social-cognitive effects of intranasal oxytocin delivered with novel Breath Powered device in adults with autism spectrum disorder: a randomized placebocontrolled double-blind crossover trial. Transl Psychiatry 7: e1136.

Quintana DS, Westlye LT, Rustan OG, Tesli N, Poppy CL, Smevik $\mathrm{H}$ et al (2015). Low-dose oxytocin delivered intranasally with Breath Powered device affects social-cognitive behavior: a randomized four-way crossover trial with nasal cavity dimension assessment. Transl Psychiatry 5: e602.

Rehm J, Mathers C, Popova S, Thavorncharoensap M, Teerawattananon Y, Patra J (2009). Global burden of disease and injury and economic cost attributable to alcohol use and alcohol-use disorders. Lancet 373: 2223-2233.

Reinhard I, Lemenager T, Fauth-Buhler M, Hermann D, Hoffmann S, Heinz A et al (2015). A comparison of region-of-interest measures for extracting whole brain data using survival analysis in alcoholism as an example. J Neurosci Methods 242C: 58-64.

Rich ME, Caldwell HK (2015). A role for oxytocin in the etiology and treatment of schizophrenia. Front Endocrinol (Lausanne) 6: 90.

Rimondini R, Arlinde C, Sommer W, Heilig M (2002). Long-lasting increase in voluntary ethanol consumption and transcriptional regulation in the rat brain after intermittent exposure to alcohol. FASEB J 16: 27-35.
Sanchis-Segura C, Spanagel R (2006). Behavioural assessment of drug reinforcement and addictive features in rodents: an overview. Addict Biol 11: 2-38.

Sarnyai Z (2011). Oxytocin as a potential mediator and modulator of drug addiction. Addict Biol 16: 199-201.

Sarnyai Z, Kovacs GL (1994). Role of oxytocin in the neuroadaptation to drugs of abuse. Psychoneuroendocrinology 19: 85-117.

Sarnyai Z, Kovacs GL (2014). Oxytocin in learning and addiction: from early discoveries to the present. Pharmacol Biochem Behav 119: 3-9.

Sauer C, Montag C, Reuter M, Kirsch P (2013). Imaging oxytocin $\times$ dopamine interactions: an epistasis effect of CD38 and COMT gene variants influences the impact of oxytocin on amygdala activation to social stimuli. Front Neurosci 7: 45.

Sheedy D, Garrick T, Dedova I, Hunt C, Miller R, Sundqvist N et al (2008). An Australian Brain Bank: a critical investment with a high return!. Cell Tissue Bank 9: 205-216.

Silva SM, Madeira MD, Ruela C, Paula-Barbosa MM (2002). Prolonged alcohol intake leads to irreversible loss of vasopressin and oxytocin neurons in the paraventricular nucleus of the hypothalamus. Brain Res 925: 76-88.

Sivukhina EV, Dolzhikov AA, Morozov Iu E, Jirikowski GF, Grinevich V (2006). Effects of chronic alcoholic disease on magnocellular and parvocellular hypothalamic neurons in men. Horm Metab Res 38: 382-390.

Sommer WH, Rimondini R, Hansson AC, Hipskind PA, Gehlert DR, Barr CS et al (2008). Upregulation of voluntary alcohol intake, behavioral sensitivity to stress, and amygdala crhr1 expression following a history of dependence. Biol psychiatry 63: 139-145.

Spanagel R, Durstewitz D, Hansson A, Heinz A, Kiefer F, Kohr G et al (2013). A systems medicine research approach for studying alcohol addiction. Addict Biol 18: 883-896.

Stevenson JR, Young KA, Bohidar AE, Francomacaro LM, Fasold TR, Buirkle JM et al (2017). Alcohol consumption decreases oxytocin neurons in the anterior paraventricular nucleus of the hypothalamus in Prairie Voles. Alcohol Clin Exp Res 41: 1444-1451.

Striepens N, Kendrick KM, Hanking V, Landgraf R, Wullner U, Maier W et al (2013). Elevated cerebrospinal fluid and blood concentrations of oxytocin following its intranasal administration in humans. Sci Rep 3: 3440.

Toloczko DM, Young L, Insel TR (1997). Are there oxytocin receptors in the primate brain? Ann NY Acad Sci 807: 506-509.

Uhrig S, Hirth N, Broccoli L, von Wilmsdorff M, Bauer M, Sommer $C$ et al (2016). Reduced oxytocin receptor gene expression and binding sites in different brain regions in schizophrenia: a postmortem study. Schizophr Res 177: 59-66.

Uhrig S, Vandael D, Marcantoni A, Dedic N, Bilbao A, Vogt MA et al (2017). Roles for L-type calcium channel subtypes in alcohol dependence. Neuropsychopharmacology 42: 1058-1069.

van Amsterdam J, van den Brink W (2013). The high harm score of alcohol. Time for drug policy to be revisited? J Psychopharmacol 27: 248-255.

Vollstädt-Klein S, Wichert S, Rabinstein J, Buhler M, Klein O, Ende $\mathrm{G}$ et al (2010). Initial, habitual and compulsive alcohol use is characterized by a shift of cue processing from ventral to dorsal striatum. Addiction 105: 1741-1749.

von Hagens G, Whalley A, Maschke R, Kriz W (1990). Schnittanatomie des menschlichen Gehirns. Steinkopff: Darmstadt, Germany.

Walker BM, Zorrilla EP, Koob GF (2011). Systemic kappa-opioid receptor antagonism by nor-binaltorphimine reduces dependenceinduced excessive alcohol self-administration in rats. Addict Biol 16: 116-119.

Woolley JD, Arcuni PA, Stauffer CS, Fulford D, Carson DS, Batki S et al (2016). The effects of intranasal oxytocin in opioiddependent individuals and healthy control subjects: a pilot study. Psychopharmacology (Berl) 233: 2571-2580. 
Woolley JD, Chuang B, Lam O, Lai W, O'Donovan A, Rankin KP et al (2014). Oxytocin administration enhances controlled social cognition in patients with schizophrenia. Psychoneuroendocrinology 47: 116-125. Yoshida M, Takayanagi Y, Inoue K, Kimura T, Young LJ, Onaka T et al (2009). Evidence that oxytocin exerts anxiolytic effects via oxytocin receptor expressed in serotonergic neurons in mice. $J$ Neurosci 29: 2259-2271.

You ZD, Li JH, Song CY, Wang CH, Lu CL (2000). Chronic morphine treatment inhibits oxytocin synthesis in rats. Neuroreport 11: 3113-3116.
Zanos P, Georgiou P, Wright SR, Hourani SM, Kitchen I, WinskySommerer $\mathrm{R}$ et al (2014a). The oxytocin analogue carbetocin prevents emotional impairment and stress-induced reinstatement of opioid-seeking in morphine-abstinent mice. Neuropsychopharmacology 39: 855-865.

Zanos P, Wright SR, Georgiou P, Yoo JH, Ledent C, Hourani SM et al (2014b). Chronic methamphetamine treatment induces oxytocin receptor up-regulation in the amygdala and hypothalamus via an adenosine A2A receptor-independent mechanism. Pharmacol Biochem Behav 119: 72-79.

Supplementary Information accompanies the paper on the Neuropsychopharmacology website (http://www.nature.com/npp) 